\title{
Making an Administrative Trustee Agent Accountable: Reason-Based Decision Making within the Kyoto Protocol's Clean Development Mechanism
}

\author{
Thomas Gehring and Isabel Plocher \\ Otto-Friedrich-University Bamberg
}

\begin{abstract}
Decisions within the Clean Development Mechanism (CDM) of the Kyoto Protocol are made by an expert body that acts as a trustee agent of the member states. Trustee agents help overcome the credible commitment problems of their principals and promise reason-based decisions. In contrast to traditional principal-agent settings, trusteeship relations are typically triadic. Beside the preferences of the principals and the trustee, decision criteria provide an external point of reference. They reflect the principals' long-term interest and define the trustee's decision rationale. The triadic structure helps protect the autonomy of trustees and allows for making them accountable for their decisions. Accountability mechanisms intend to ensure that a trustee's decisions are in line with established decision criteria. Against this backdrop, we explore the incentives created by the existing institutional arrangement for the making of CDM decisions and examine selected cases. We conclude that CDM arrangements provide a model for nonpartisan international regulation.
\end{abstract}

Delegation of decision-making authority to international institutions raises the problem of accountability of the power-wielding agents (Grant and Keohane 2005; Scott 2000). It occurs whenever the member states of an international institution establish a secretariat, a scientific committee, or any other entity entrusted with particular functions. Standard principal-agent theory conceives of delegation as a contractual arrangement in which the principal grants authority to an agent to act on behalf of himself, whereby the grant is revocable and limited in time or scope (Hawkins et al. 2006, 7). Accountability arrangements are intended to limit the power-wielding agents' ability to acquire an undesirably extensive degree of autonomy (Nielson and Tierney 2003) and to avoid cooperation pathologies (Barnett and Finnemore 2004).

This article examines how administrative trustee agents can be made accountable for their decisions without jeopardizing their proper functioning. The design of arrangements for holding trustees accountable is particularly demanding. Trustees are established in response to their principals' self-perceived tendency to behave opportunistically in specific decision situations. Independent regulatory agencies (Thatcher 2002) and central banks (Gilardi 2007) as well as domestic and international courts (Alter 2008) illustrate that political actors may gain an interest in committing themselves credibly not to intervene into 
day-to-day decision making (Moravcsik 1998, 472). In these cases, recommendations of standard principal-agent theory for comparatively close oversight of agents are not applicable, because trustees ought to act differently from what their principals would have done in their place (Majone 2001a). Close oversight by the principals and the permanent re-contraction threat suggested by standard principal-agent theory (Epstein and O'Halloran 1999; Kiewiet and McCubbins 1991) would inevitably undermine a trustee's ability to fulfill her regulatory functions. Instead, accountability arrangements must be designed so as to ensure problem-adequate decision making without undermining the relationship between the member states of an international institution and their trustee agent.

The approval of climate-friendly projects under the Clean Development Mechanism (CDM) of the Kyoto Protocol to the United Nations Framework Convention on Climate Change raises the accountability problems involved in delegation of administrative decisions to trustees. Approval decisions have been almost entirely assigned to an executive board that enjoys comparatively farreaching autonomy and operates like an independent regulatory agency similar to what is known in domestic political systems (Thatcher 2002) and the European Union (Gehring and Krapohl 2007). Under the Protocol, most industrialized countries have accepted to reduce their emissions of certain greenhouse gases by a fixed percentage (see generally Oberthür and Ott 1999). The CDM allows them to implement their obligations partly through projects reducing emissions in developing countries (Netto and Barani Schmidt 2005). As emission reductions generated by CDM projects increase the amount of tradable emission permits, the CDM threatens to undermine the control system of the Kyoto Protocol (Yamin and Depledge 2004, 166). CDM activities are expected to create emission credits worth billions of dollars (Wara 2006).

Discussion of the autonomy of trustee agents in international relations has so far largely centered on international courts and adjudication bodies. International or supranational courts such as the European Court of Justice, the European Court of Human Rights, and the World Trade Organization Appellate Body are beyond doubt among the most autonomous trustees in international relations. The adherents of principal-agent theory emphasize that the member states of relevant institutions always retain the power to re-contract and thus create a permanent threat of sanctions (Garrett, Kelemen, and Schulz 1998). In contrast, judicial governance scholars argue that the principals' ability to use this power and to curtail the autonomy of adjudicative trustees is severely restricted (e.g., Alter 2006; Burley and Mattli 1993). Remarkably, the conflict has been largely framed as a dyadic one on whether decisions reflect the preferences of the principals or those of their agents. Only recently, Alter $(2008,40)$ suggested that trustees decide in the interests of some "putative beneficiary that differs from the principal" and that this beneficiary may be an entirely artificial construction. While this suggestion originates from inductive inference rather than from deductive reasoning, it draws attention to an important aspect of trusteeship decision making: Trustees can point to some external point of reference that transforms the ever-looming dyadic conflict between principals and agents into a triadic one.

Against the backdrop of the CDM approval mechanism, this article makes three theoretically relevant contributions to the debate on the logic of delegation to trustee agents and its accountability implications. First, it argues that trusteeship delegation always relies on a specific rationale for delegated decision making as an external point of reference that is distinct from both the aggregate preferences of the principals in a given decision situation and from possible preferences of the trustee agents. In an evolving division of labor, the principals define the rationale for trusteeship decision making, while trustees execute this rationale in subsequent decisions. In this triadic relationship, trustees cannot 
simply replace the preferences of their principals by their own ones. In case of tension with their principals on the content of a particular decision, however, administrative or judicial trustees can refer to these decision criteria (Alter 2008). The commonly accepted points of reference help preserve the autonomy of trustee agents vis-à-vis their principals and limit their autonomy to adopt arbitrary decisions that are difficult to justify in light of established decision criteria.

Second, accountability mechanisms ought to ensure that a trustee's decisions are in line with her externally given decision criteria. These criteria allow for appraising these decisions. Appropriately designed accountability mechanisms will seek to diminish the impact of power and parochial interests of all possibly interested stakeholders, states, and non-state actors alike, while enhancing the influence of interventions that advance particularly well-reasoned arguments. Third, the article expands the empirical foundation of the discussion on trusteeship decision-making in international relations to administrative trustees that pose somewhat different problems than adjudicative trustees. While both sorts of trusteeship decision making share some characteristics and are charged with evaluating the merits of pending cases in light of valid decision criteria, decision making by administrative trustees involves wider margins of discretion. It occurs prior to a possible change in the state of affairs and it is not based upon a single well-defined logic of reasoning. In contrast, adjudication by independent courts follows the well-established logic of legal reasoning, it evaluates an existing state of affairs after the fact, and it relies on the fiction that it is limited to the application of existing rules to specific cases (Shapiro 1981; Stone Sweet 2004, 5).

In the first part of this article, we examine two different logics of delegation and their implications for the design of appropriate accountability mechanisms. We then discuss arrangements to hold trustee agents accountable for their decisions. Subsequently, we briefly explore the relevance of the proper operation of the CDM for the success of the Kyoto Protocol and the reasons for the remarkably far-reaching delegation of decision powers. Against this backdrop, we explore the incentives created by the existing institutional arrangement for the making of CDM decisions. While not intervening into the day-to-day operation of the CDM, the Conference of the Parties ( $\mathrm{CoP})$ as the regime's supreme decision-making body has enacted a set of substantive standards and tight procedures. Delegated decision making about CDM projects involves several bodies with specific functions and is closely observed by the interested public, thus establishing a system of horizontal accountability among these bodies and actors. Finally, we examine three contentious project-specific decisions to explore obstacles to criteria-based CDM decision making. Such obstacles originate from uncertainty and the partial absence of reliable decision criteria. We conclude that the CDM arrangements provide a model for nonpartisan international regulation.

\section{Accountability of Trustee Agents in International Institutions}

\section{The Decision Rationale of Trustee Agents}

Delegation of decision-making competencies can follow either of two distinct theoretical logics (Majone 2001b). Principals may establish an agent to reduce transaction costs by relieving themselves of certain tasks, acquiring expertise, or limiting the complexity of decision making (Hawkins et al. 2006, 12-20; Koremenos, Lipson, and Snidal 2001, 766). Principals may also establish a trustee to protect their own well-perceived long-term interests.

Agents established to reduce the transaction costs of decision making are, despite the evolving division of labor, expected to apply the same decision rationale as their principals would have done in their place. Accordingly, this type of delegation typically creates the well-known dyadic principal-agent constellation. 
Principals seek to establish oversight arrangements and make the agents "vertically" (Schmitter 1999) or "hierarchically" accountable to themselves (Grant and Keohane 2005, 36), because agents might otherwise pursue their own interests (Barnett and Finnemore 2004; Moe 1990, 121). Oversight intensity is merely limited by the costs of monitoring and controlling an agent's activities. Agents should face significant sanctions if deviating from their principal's expectations (e.g., limitation or redefinition of competencies, budgetary constraints, and changes of personnel) to create a rational expectation that it is in their own interest to follow the decision rationale of their principals as closely as possible (Epstein and O'Halloran 1999; Kiewiet and McCubbins 1991). The limitation of an agent's decision-making powers to preparatory functions is the predominant arrangement within international institutions for ensuring that the principals' decision rationale is not violated. In this case, an agent will have to anticipate the aggregate preferences of her principals to gain influence. This is true for the secretariats of international environmental regimes, such as the Convention on International Trade in Endangered Species (Gehring and Ruffing 2008), for the powerful administration of the World Bank (Nielson and Tierney 2003), and even for the Commission of the European Union, which is closely supervised by the Council of Ministers as well as numerous committees attended by the member states (Pollack 1997).

Trustee agents established to execute the member states' long-term interests are expected to apply a rationale that is systematically different from what their principals would have done in their place. Rational actors will gain an interest in committing themselves credibly to their long-term interest (Moravcsik 1998; Shepsle 1991), if their preferences are inconsistent over time (Elster 1979, 67-8; Majone 2001b). In this case, their action in a specific decision situation threatens to violate their long-term interests. The classic example is a government that negotiates with hostage-takers and thereby creates incentives for future crimes (Keech 1995, 38-40). Typically, the principals define at a given point in time $t_{0}$ a long-term interest, while being tempted to act, in a subsequent decision situation $t_{1}$, according to other, possibly equally sound, decision considerations, so that their long-term interest turns out to be undermined at point $t_{2}$. Accordingly, a trustee agent serves her principals best by executing the principals' wellperceived long-term interest, and by not adjusting to what her principals would have done in her place. The resulting decisions are expected to be "better" than those directly influenced by the principals.

In contrast to a regular principal-agent relationship, the relationship between principals and a trustee agent is triadic. The solution of conflicts between a trustee agent and her principals over the appropriate decision in a particular case is not simply a matter of hierarchy and power. The trustee agent can refer to the principals' previously defined long-term interests and ought to honor this external point of reference, even if facing pressure to adapt to the principals' case-specific preferences. It is not necessary to assume that trustee agents make their decisions on behalf of some putative beneficiary distinct from their principals, as Alter (2008, 40) suggested. This would imply that the trustee knew systematically better than her principals. It suffices to recognize that trustees can justify their decisions by referring to some decision criteria that are externally given. The triadic setting redefines the heavily discussed issue of how much autonomy trustee agents enjoy. While the adherents of principal-agent theory emphasize that the member states of relevant institutions always retain the power to re-contract and thus create a permanent threat of sanctions (Garrett, Kelemen, and Schulz 1998), judicial governance scholars argue that existing restrictions to using this power preserve the autonomy of court-trustees (Alter 2006; Burley and Mattli 1993). Ideally, trustee agents ought to be fully protected from their principals' intervention into their day-to-day business, while 
not enjoying any autonomy to deviate from the decision criteria defined by their principals.

The sincere execution of a trustee's tasks requires reason-based discourse and arguing, rather than preference aggregation and power-based bargaining. Arguing originates from the Habermasian concept of communicative action (Elster 1998; Risse 2000). In an arguing process (discourse), disputes are settled through the collective assessment of the reasons accompanying disputed propositions against commonly accepted criteria. It entangles the participants in a learning process. Discursive settlement of conflicts starkly contrasts with bargaining, that is, the arm-twisting mode of coordination that focuses on distributive effects and relies on credible threats and promises (Elster 1989, 50-96). While a bargaining outcome is as "good" as any other, because commonly accepted evaluation criteria are absent, discourse promises to produce decisions that are particularly well-reasoned in light of the decision criteria applied. Hence, an ideal trustee will evaluate the merits of existing options sincerely in light of the externally given decision criteria and choose the most convincing one.

\section{Accountability Mechanisms in Trusteeship Relations}

A prerequisite for any well-designed accountability mechanism is the definition of appropriate decision criteria as external points of reference for all actors involved. Substantive criteria indicate the long-term interests, as defined by the principals, against which action of power-wielding agents can be judged. They provide the most definitive set of instructions principals can give to their trustees and create an important ex ante accountability mechanism (Huber 2000, 400). Without such standards, a trustee lacks substantive guidance when having to appraise different options. Binding decision criteria create a sort of administrative law and thus legalize the institutional law-making process. Administrative law is a well-known instrument for controlling independent regulatory agencies in domestic political systems and in the European Union (Shapiro 2001). Moreover, binding substantive decision criteria commit all other actors involved, including the principals and private applicants, to the same set of standards.

While substantive decision criteria emerge from intergovernmental negotiations, the ensuing division of labor between principals and their trustee agents limits the room for power-based maneuvering among the former. In spite of the intense discussion on the legitimacy of international institutions and the lack of external accountability of international decisions to the broader public (Keohane 2003,141 ), it is difficult to see actors that were better legitimized than states and equally well-equipped to define the long-term interests of international society, nor that there are coordination mechanisms that were more appropriate than intergovernmental negotiations for this task. Whereas intergovernmental bargaining does not always lead to the common good, especially because of distributive interests of the negotiating parties (Elster 1989), the delegation of decisionmaking functions to a trustee agent contributes to limiting the maneuvering room for bargaining and pure preference aggregation. If principals intend to shield case-specific decisions from their immediate influence, they can affect the final decisions only through well-crafted general rules. Accordingly, they are forced to be consistent across cases (Brennan and Buchanan 1985, 28-31). Actors may even be precluded from clearly assessing their overall preferences across cases, if rules and procedures last for an unknown period of time and the universe of future cases is unknown. Under these conditions, states tend to operate under a Rawlsian "veil of ignorance" (Rawls 1971, 136-42) which will encourage even rational utility maximizers to engage in the common search of arrangements that promise acceptable outcomes irrespective of their distributive consequences. 
Trustee agents can be made accountable for their activity through a number of interrelated mechanisms which together must provide sufficiently strong incentives to ensure that decisions are reasonable, or problem-adequate, in light of the externally given decision criteria. The specific relationship between a trustee and her principals defines the design conditions for appropriate accountability arrangements. These arrangements ought both to protect a trustee's autonomy vis-à-vis her principals and to limit her ability to deviate from sincerely applying relevant decision criteria provided by the principals. By requiring the trustee to give account, they shall ensure that decisions are particularly well-reasoned and thereby implement the principals' long-term interests. Accountability arrangements may require specific forms of divided labor that assign separate decision functions to several actors (Gehring and Krapohl 2007). Functionally differentiated decision-making systems are organized according to their decision procedures that constitute institutional opportunity structures and assign selected powers to various types of actors (Garrett and Tsebelis 1996; McCubbins, Noll, and Weingast 1987).

First, the internal composition helps both commit a trustee agent to existing decision criteria and narrow the margins for arbitrary decisions. It constitutes an internal accountability mechanism. In international relations, political or judicial decisions are usually assigned to committees or court chambers, rather than to individuals or hierarchically organized bureaucracies. Corporate agents create a specific form of committee governance (Sartori 1987, 227-32). Their members tend to be faced with a stream of parallel decisions of comparatively limited scope, each of which will hardly allow the accommodation of all preferences. Actors seeking to pursue case-specific parochial interests (e.g., preferences of their government or any other relevant stakeholder) will bring committee decision-making to a stop and jeopardize cooperation altogether. Hence, committee governance requires preparedness to link decisions implicitly over time. If only the indifferent members without specific interests in a given case tend toward the solution that is best accommodated with the externally given decision criteria, this solution will almost certainly provide the focal point (Schelling 1960, 99-118) around which the expectations of all members converge. The constraints of committee governance and the necessity to find a common focal point generate a strong tendency to engage in the deliberative search for solutions that are in conformity with the mandatory decision criteria.

Second, the establishment of a system of checks and balances among different agents makes these agents "horizontally" accountable to each other (O'Donnell 1999), and helps preclude that they overstep their margins of discretion. A case-specific decision does not have to be delegated to a single trustee. On the one hand, the scientific or technical preparation of a decision may be dealt with separately from its final adoption. A subsystem which is responsible for the technical or scientific preparation provides a niche for expertise. Experts will gain an incentive to submit convincing recommendations, if their conclusions have to be accepted by another body to become effective. Recommendations submitted by a preparatory expert body will almost automatically change the situation of the subsequent decision body, because they set the agenda for this stage and enhance the costs of deviating decisions (Gehring 1999; Pollack 1997) - unless there are good reasons for this step. On the other hand, specific review procedures may be established that make a trustee agent directly accountable to another trustee agent. Judicial oversight of agency decision making constitutes an important pillar of accountability within domestic political systems (Shapiro 1988) and within the European Union (Gehring and Krapohl 2007). Unfortunately, effective mechanisms for judicial control of administrative decision making within international institutions are largely absent from international relations. A rare exception is the review procedure 
within the World Bank, with an inspection panel in its center (Clark, Fox, and Treakle 2003).

Third, a trustee, or a more complex decision-making system, may be held externally accountable to the wider public. Evidently, this type of accountability must not replace the decisions of the former with the preferences of the latter. Instead, interested public actors, including non-governmental organizations (NGOs), may be granted an opportunity to follow decision making and, possibly, to intervene with arguments and information. Competent non-state actors can support delegated decision making directed at identifying the most problem-adequate solution. Observation of decision making by an interested public increases the costs of adopting decisions that are unconvincing and less problem-adequate than possible, because such distortions will be more easily detected. However, public access should be highly selective. Power-based pressure by well-organized stakeholders would undermine the choice of reasonable decisions, and unlimited access threatens to congest the decision process altogether.

Fourth, decision-makers in all stages of the process can be mandated to "give reasons" (Shapiro 2002) for their decisions to increase the incentive to adopt well-reasoned decisions, rather than those based upon aggregated preferences and power. The giving reasons requirement commits decision-makers to relate their decisions expressly to mandatory decision criteria, and it facilitates the ex post appraisal of intermediate or final decisions in light of valid criteria. It also forces advocates of partisan interests to justify their interests with reasons that convince other actors (Elster 1998, 104).

Finally, even a trustee will always be externally accountable to her principals that have granted, and can at any time revoke authority (Grant and Keohane 2005, 29). This is the most sensitive part of a comprehensive accountability scheme. While principals retain their power to re-contract, that is, to redefine the trustee's task or to withdraw decision-making authority altogether, they cannot use this power without jeopardizing the proper operation of the regulatory system altogether. Any intervention into the day-to-day business of the trustee agent will inevitably undermine her ability to act according to the principals' previously defined long-term interests. Therefore, this form of external accountability must remain latent; it is not suitable for the fine-tuning of the trustee's case-specific decisions. However, the member states may well readjust substantive criteria and procedures at any time so as to direct the regulatory process. This will be particularly important, if delegated decisions appear to be not in conformity with decision criteria, or if the principals' long-term interests have changed over time.

These mechanisms are to some degree functionally equivalent. Together, they reduce the risk that trustees abuse their competencies, while avoiding ad hoc intervention of principals into case-specific decision making. Trustee decisionmakers are systematically deprived of their ability to bargain or to pursue partisan interests, because badly reasoned (unconvincing) decisions do not remain undetected. If the regulatory system is carefully designed, so as to ensure that regulatory decisions are not systematically distorted by the undesired intervention of powerful stakeholders, accountability will be incorporated into the intrainstitutional decision process and the principals can afford to abstain from overseeing day-to-day activities of their trustees directly. In this case, effective internal (horizontal) accountability of decision-makers to other actors within the decision-making system ensures that decisions are in line with the substantive rules that reflect the long-term interests of the principals. And vice versa: less effective internal accountability will create undesired autonomy for trustees and increase the necessity for intervention by the principals, even though this might tacitly undermine the established division of labor. 


\section{The Nature of CDM Decision Making}

The CDM promises to make climate protection policy more cost-effective. It allows industrialized countries (annex-I-countries), or private companies located in these countries, to discharge part of their emission reduction obligations under the Kyoto Protocol through projects located in developing countries (non-annex-I-countries). If energy efficiency in the host country is lower than in the industrialized country, a given reduction of emissions can be achieved with lower investment efforts than at home. CDM projects are expected to create emission credits worth billions of dollars (Wara 2006). By the end of 2007, approved CDM projects amounted to more than 100 million certified emission reductions (CERs), each equivalent to $1 \mathrm{~T}$ of $\mathrm{CO}_{2}$ emissions. Given that a CER sells currently (May 2008) at about $€ 16$ (25 US\$), and within the European Union even at about $€ 25$ (40 US\$; http://www.carbonpositive.net), approved CDM projects have a volume of about 2.5 billion US $\$$ - with a dramatic increase in projects and volume (see Table 1). Profits are attractive, because investment costs for many project types are quite low (Wara 2006).

However, the CDM can seriously undermine the commitment system of the Kyoto Protocol if it is poorly administered (Meijer and Werksman 2005, 192). A $\mathrm{CDM}$ project creates emission reduction credits that are subtracted from the obligations of the relevant industrialized country, whereas the host country does not incur any reduction obligations under the current Protocol. CERs may be transformed into tradable emission permits and sold to other member states (for the European Union, see Lefevre 2005). The overly generous creation of CERs from poorly evaluated CDM projects would thus seriously undermine the collective intention of the member states to stabilize, or reduce, greenhouse gas emissions (Yamin and Depledge 2004, 166).

The administration of the CDM raises a serious credible commitment problem. While all member states should have a long-term interest in the sincere operation of the approval mechanism, they tend to pursue different interests in regard to a particular project. Countries expecting difficulties in fulfilling their emission reduction obligations depend on the approval of a sufficient number of CDM projects (Boehmer-Christiansen and Kellow 2002). They require protection against an overly restrictive application of the CDM and should be confident that emission reductions from costly projects located abroad are sincerely credited to their emission budgets. However, they have a systematic interest in the generous approval of their own CDM projects, even if tacitly undermining the Protocol's overall reduction scheme. In contrast, countries intending to implement their reduction obligations at home are interested in ensuring that CDM projects do not create tradable emission certificates without corollary emission reductions, because this would disadvantage their economies and jeopardize climate protection efforts. They might favor an overly restrictive approval of CDM project, because they do not benefit at all from these projects. Developing countries welcome the generous approval of CDM projects, which promises access to capital and energy-efficient technology, but they also have an interest in not allowing industrialized countries to slip away from their obligations to protect the global climate.

TABle 1. Increase in Project Activities and Issued CERs

\begin{tabular}{lccc}
\hline & 2005 & 2006 & 2007 \\
\hline Registered projects & 14 & 387 & 895 \\
Issued CERs & - & $17,050,760$ & $102,544,493$ \\
\hline
\end{tabular}

Source: Kyoto Protocol Secretariat; CER, certified emission reduction. 
Due to their divergent interests regarding specific CDM projects, the member states would almost surely have been confronted with continuing decision problems, if they had chosen to approve CDM projects during their annual CoP meetings. The CDM has been promoted by states that were reluctant to engage in significant emission reductions, including the United States, because it allows greater flexibility and cost-effectiveness in fulfilling the reduction-commitments (Yamin and Depledge 2004, 46), but it aroused criticism by the European Union, some developing countries like the Alliance of Small Island States (AOSIS), and environmental NGOs, all of them fearing that it could provide a loophole in the Kyoto Protocol (Meijer and Werksman 2005, 192; Schröder 2001, 86). As the scheme is not self-enforcing, but requires significant secondary decision making, every single decision on a project or package of projects would almost inevitably be burdened with the general conflict over the appropriateness of the CDM scheme. Moreover, considering the size of possible investments and the systematically mixed motives of virtually all groups of member states involved, it would be all too optimistic to assume that states would, in the absence of an effective commitment to nonpartisan and criteria-based evaluation of CDM projects, systematically avoid bargaining over the compilation of project packages and their distributive effects. The occasionally occurring struggle over specific decision criteria and even over the treatment of comparatively limited project types (see below: The HFC Avoidance Projects) illustrates the continuing potential for intergovernmental conflict and the preparedness of the member states to preserve their interests by bargaining.

The nature of the decision problem explains why the member states could agree, in their own interests, on establishing a decision-making apparatus that is, in its day-to-day business, remarkably independent from direct intervention by the CoP. In assigning project decisions to a trustee agent, they avoided permanent conflict and committed themselves credibly to their collectively defined long-term interest.

\section{Accountability of an Administrative Trustee: The Approval of CDM Projects}

The procedural rules enacted by the CoP reflect the intention of the Kyoto Protocol parties to produce CDM approval decisions in a process that is not dominated by partisan political forces. Approval decisions are fully assigned to the CDM Executive Board composed of 10 experts and 10 alternates from the member states acting in a personal capacity. The Board members are elected for a period of 2 years. They may serve a maximum of two consecutive terms. Only the Board itself may, for serious reasons, suspend and ask the CoP to terminate the membership of one of its members (Decision 3/CMP.1, Kyoto Protocol 2005a, 6-29). ${ }^{1}$

Member states sacrificing their power to influence the content of important decisions through traditional intergovernmental bargaining must be sure that the approval procedure will produce acceptable results. They seek to ensure through several accountability mechanisms that power-based interventions by states and non-state stakeholders are systematically sorted out and approval decisions are consistent with their general intentions.

\section{Substantive Decision Criteria as Commonly Accepted Points of Reference}

As part of its Marrakech Accords of 2001, the CoP adopted a voluminous set of detailed substantive provisions establishing the approval process and defining the rights and responsibilities of the actors involved. These rules were refined

\footnotetext{
1 Documents are available at the homepage of the regime: http://www.unfccc.int.
} 
later and approved in 2005 by the members of the Kyoto Protocol upon the treaty's entry into force.

The most important substantive approval criterion is the requirement that emission reductions achieved by a CDM project be additional to any that would have occurred in the absence of the project. Projects shall generate real, measurable, and long-term benefits related to the mitigation of climate change (Kyoto Protocol, art. 12). The additionality criterion is an indispensable condition for the appropriate operation of the CDM. If credited emission reductions were not additional, CDM projects would inevitably undermine the general scheme of the Protocol (see above: The Nature of CDM Decision-Making). The criterion is impartial and does not privilege certain member states over others. Accordingly, the principle was not contested during the negotiations (Niizawa 2003; Sales and Kherlakian Sabbag 2007).

The CoP has attempted to define the additionality criterion more clearly. Its speculative nature and inherent vagueness originates from the necessity to elaborate a counterfactual scenario of how emissions would have developed in the absence of a proposed project (Meijer and Werksman 2005, 199-200; Repetto 2001, 311). The CoP stipulated that the baselines reflect a transparent and conservative account of approaches, assumptions, methodologies, parameters, data sources, key factors, as well as relevant national policies and circumstances (Decision 3/CMP.1; Kyoto Protocol 2005a, 6-29). Moreover, it requested the approval apparatus to develop suitable methodologies for the development of baselines capable of proving that projects would otherwise not have been undertaken. In 2001, it adopted criteria for new methodologies for baselines and monitoring (Decision 17/CP.7, UNFCCC 2001, 20-49). Ways of calculating additionality have been compiled in a "Tool for the Demonstration and Assessment of Additionality" (Report on EB 39 [2008], Kyoto Protocol 2008, 6).

Other substantive criteria commit the decision-makers to more specific guidelines applying to particular cases. The CoP limited sink-related CDM projects to reforestation and afforestation activities and spelled out detailed eligibility criteria for afforestation areas (Decision 5/CMP.1, Kyoto Protocol 2005a, 6180 ) - thus excluding other possible sinks such as subsoil storage of compressed greenhouse gases (Scholz and Noble 2005, 266). It excluded nuclear power stations from CDM activities (Decision 17/CP.7, UNFCCC 2001, 20-49). It declared that local, regional, or national policies and standards cannot be considered as CDM projects, whereas projects under a local, regional, or national program of action can, if meeting the general requirements (Decision 7/CMP.1, Kyoto Protocol 2005a, 93-99). It stipulated that an increase of emissions as a consequence of an emission-reducing CDM project (leakage) shall be part of the calculation. These criteria limit the discretion of the CDM approval apparatus considerably, but they are obviously more prone to political compromise. For example, the exclusion of nuclear power stations surely reflects a broadly shared position among environmentally concerned countries and NGOs, but it removes from the CDM an emission reduction technique that is employed in industrialized countries and does become part of the calculation of emissions and emission reductions of these countries.

Some other possible criteria for the eligibility of CDM projects have not been adopted by the CoP and are thus not subject to CDM decision making. Demanding that CDM projects do not divert funds from established development aid, developing countries had, unsuccessfully, attempted to expand the additionality criterion to developmental considerations (Yamin and Depledge 2004, 177). Despite some vague language within the Kyoto Protocol (art. 12), CDM decision-makers are also not mandated to assess whether a proposed project contributes to sustainable development, while member states as well as companies and organizations may voluntarily require a sustainability check for their projects (Kenber 2005, 272-8). 
The substantive criteria enacted by the member states narrow the discretion in the approval process and thus bind the approval apparatus. Although providing the clearest possible degree of guidance in general terms, they still leave a considerable margin for interpretation (Niizawa 2003). In essence, they reflect a set of points that should be considered when evaluating a methodology and validating a project, rather than readily applicable substantive standards. However, they require the Executive Board to provide convincing reasons for the support of its decisions and may thus serve as standards for the appraisal of its activities.

\section{The Approval of Assessment Methodologies: Strong Accountability Mechanisms Ensure Reasonable Application of General Decision Criteria}

Several accountability mechanisms are intended to ensure that the Executive Board sincerely adheres to its task and does not abuse its competencies. The approval of assessment methodologies for the validation of CDM projects is the Board's most far-reaching task, because it amounts to rule-making. In essence, a methodology for the calculation of emission reductions of a particular project type constitutes a set of more detailed validation criteria. Also, approved methodologies are published and may be employed by other applicants for their own projects. If approval decisions are to be made in a nonpartisan and problem-oriented manner, the accountability mechanisms must create sufficient incentives to ensure that stakeholders are deprived of their ability to resort to their bargaining power or, at least, that such action does not successfully influence the content of approval decisions.

First, the country-specific composition of the Board and its decision rules help sort out parochial interests, which members might occasionally seek to pursue, and make the members internally accountable to each other. Its 10 members and 10 alternates originate from four industrialized countries committed to specified emission reductions and six developing countries representing possible host countries of CDM projects. ${ }^{2}$ Decisions are to be made by consensus whenever possible, otherwise by a three-fourths majority. Accordingly, any attempt by one of the two possible camps to pursue partisan interests will immediately slow down the speed of the decision-making process or block it altogether (Matsuo 2004, 233-4). The Board is thus subject to the influence of committee governance (Sartori 1987, 227-32) and the necessity to find a commonly accepted focal point for every single decision. As a methodology focuses on very specific types of projects, it will be difficult to simply accommodate the preferences of all Board members through bargaining. If only the indifferent members tend toward the solution that is best accommodated with the mandatory decision criteria, this solution will almost certainly provide the focal point on which the expectations of all members converge. In practice, the implications of committee governance are reinforced by the fact that the Board members act in a personal capacity and that the Board decides almost exclusively by consensus (Netto and Barani Schmidt 2005, 178).

Second, the approval procedure creates a multistage decision process and involves several different actors (see Figure 1). An assessment methodology is always elaborated by a private or state-related applicant. Applicants have an interest in overestimating the emission reductions generated by their CDM projects and in promoting methodologies resulting in comparatively high baselines

\footnotetext{
2 The Board is composed of one member from each of the UN-regions (Africa, Asia, Latin America and the Carribean, Central and Eastern Europe, Western Europe and Others) as well as two other members from Annex I Parties (industrialized countries), two other members from Non-Annex I Parties (developing countries) and one member from the AOSIS. See Rules of Procedure for the Executive Board, Dec. 4/CMP.1, 32, Kyoto Protocol 2005a.
} 


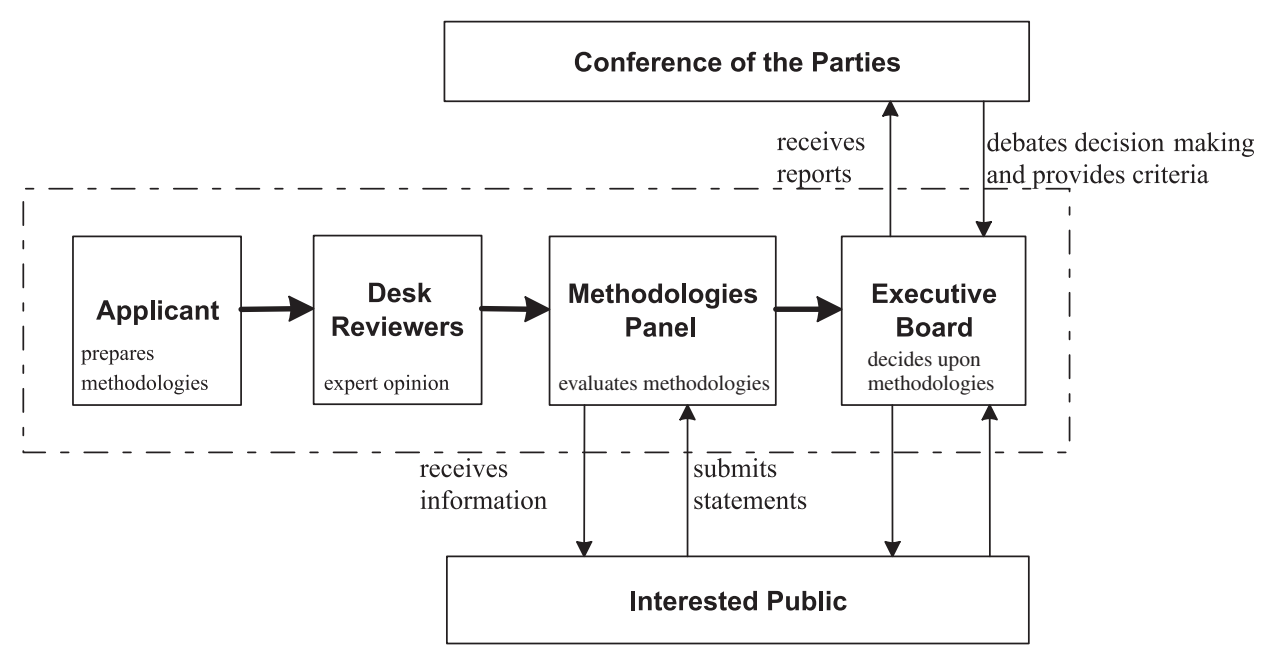

Fig. 1. Methodology Approval Procedure

(Niizawa 2003, 99), but they must seek to convince the approval apparatus that their proposed methodology is in line with the general criteria. In this sense, applicants set the agenda, but they are accountable to the subsequent stages of the approval apparatus. Submitted methodologies are evaluated by the Methodologies Panel, a subsidiary body of the Executive Board. The Panel is charged with advising the Board on methodologies for the establishment of baselines and monitoring procedures. Its 15 members are experts acting in their personal capacity (Report on EB 02 [2002], Kyoto Protocol 2002, 9). The Panel constitutes the center of expertise in the approval process, but it does not have final decision power. It scrutinizes every submitted methodology thoroughly in a police patrol manner (for the difference between accountability mechanisms following the designs of "police patrol" and "fire alarm," see McCubbins and Schwartz 1987). Formally, the Panel merely enjoys an advisory function. Its influence on the final decisions depends on whether or not its recommendations are accepted by the Executive Board. It provides detailed reasons explaining its recommendations. Hence, the Methodologies Panel as a whole is accountable to the Executive Board and has a strong incentive to generate sound expert advice, even if individual members might occasionally have personal preferences or pursue the interests of stakeholders. The final decisions are made by the Executive Board. However, the agenda for Board discussions is set by the Methodologies Panel's assessment and recommendation. Board members desiring to promote decisions deviating from Panel recommendations must persuade most of their co-members that their position is more convincing than the recommendation of the Panel. So far, the Executive Board has taken the opinions of the Methodologies Panel very seriously. Only in four out of the first 45 registered methodologies did the Board decide more rigidly than the Panel had recommended (http://www.cdm.unfccc.int/methodologies).

Third, the decision-making bodies are externally accountable to the interested public. Public observers constitute an additional "fire alarm" system. While not having formal rights to complain or challenge a decision, they may alert member states. The procedure is highly transparent and provides opportunities for the interested public (e.g., NGOs and research institutes) to submit statements. Proposed methodologies are, together with a comment form, made public on the Internet. Comments from the public have to be considered by the Methodologies Panel. Evidently, this access is highly selective. Only technically or 
scientifically competent actors can successfully seize the opportunity to influence the evaluation process by providing reasonable arguments or relevant information related to the valid decision criteria. Meetings of the Executive Board are also open to observers from all member states and from accredited organizations (i.e., mostly NGOs). Most parts of the discussion are even broadcast via Internet, and technical documents are made public upon adoption of the decision. Hence, Board members cannot expect that badly reasoned decisions will remain undetected (Meijer and Werksman 2005, 205).

Finally, the Executive Board is generally accountable to the CoP. The Board reports regularly to the $\mathrm{CoP}$ and its reports are discussed in the plenary. While the CoP does not comment on single projects, it carefully observes activities, at least in the current start-off period. It also seems to be prepared to readjust the framework of substantive and procedural regulations, if deemed appropriate. In guidance documents, it responds to questions raised by the Executive Board and requests the Board to undertake certain measures (e.g., Decision 7/CMP.1, Kyoto Protocol 2005a, 93-99) or elaborate further rules (Decision 3/CMP.1, Kyoto Protocol 2005a, 6-29). The CoP is also formally empowered to request revision of approved methodologies (Decision 3/CMP.1, Kyoto Protocol 2005a, 6-29), but it is not entitled to adopt its own ones. This CoP intervention power cannot be more that an "emergency break," because its employment would automatically undermine the division of labor between the principals and their administrative trustee. For the regular revision of the general direction of approval decisionmaking, the CoP will have to adjust its general rules, rather than intervening into specific decisions.

Altogether, the procedure for the approval of new methodologies is designed to deprive all bodies and individual decision-makers involved of their ability to deviate from well-reasoned decisions consistent with the general criteria. While influence by the Methodologies Panel (i.e., the formally weakest body) relies almost exclusively on its expertise, the Executive Board is, by several complementary accountability mechanisms, deprived of its ability to compromise and bargain. Actors from the broader public can intervene into the process, but only with convincing arguments. The CoP, although able to request revision of an approved methodology, is kept from simply replacing an undesired decision by its own, and it cannot easily intervene into the regular approval process.

\section{Project-Specific Decisions: Several Layers of Accountability}

The validation of CDM projects and the eventual certification of emission reduction credits are assigned to "operational entities" (i.e., private technical auditing firms contracted by the applicants of CDM projects). Validation is the assessment of whether or not a project meets the relevant criteria and whether or not the methodologies are correctly applied; it ends with the registration, or rejection, of the project. Verification refers to the assessment of whether or not the projected emission reductions have actually been realized. One operational entity assesses a proposed CDM project in the validation stage and issues a request for registration of the project, if it finds the eligibility criteria to be fulfilled (Decision 3/CMP.1, Annex, Kyoto Protocol 2005a, 14-17). A different operational entity audits the regular assessment reports by the applicants of a CDM project in the certification stage and regularly monitors the project according to the monitoring methodology. Auditing includes on-site visits. Eventually, this second operational entity recommends to issue emission reduction credits, if it finds the reports to be reliable. A validated CDM project is automatically registered after 8 weeks, and the request to certify emission reduction credits is accepted after 15 days, unless a review is requested by competent actors (Decision 17/CP.7, UNFCCC 2001, 20-49 and Decision 4/CMP.1, Kyoto Protocol 2005a, 30-60). 
Several accountability mechanisms are in place to ensure that operational entities testify sincerely. These entities compete for validation and certification contracts and could be tempted to evaluate the project more positively than justified. However, they face two severe sanctions for false testimony. On the one hand, they can lose their reputation and market opportunities. Operational entities must be accredited by the Executive Board and designated by the CoP. Accreditation is reviewed periodically and there is a constant threat of nonrenew$\mathrm{al}^{3}$. On the other hand, an operational entity may be held liable for emission credits that are falsely issued because of incorrect certification (Decision 17/CP.7, UNFCCC 2001, 20-49; Yamin and Depledge 2004, 172). Therefore, operational entities tend to refuse projects that are considered as incompatible with CDM criteria (Michaelowa 2005, 145).

Operational entities are directly accountable to the Executive Board, which has the formal right of facultative review. This right has been used intensely, so that the original "fire alarm" mechanism has been tacitly transformed into a "police patrol" mechanism (McCubbins and Schwartz 1987). A review of the request to register a project or to certify emission credits may be demanded by each of the parties involved in the project or by at least three members of the Executive Board. The demand must be accompanied by reasons associated with the validation or certification requirements and by supporting documentation (Decision 4/CMP.1, Kyoto Protocol 2005a, 30-60). The actors formally entitled to instigate review proceedings may be alerted by interested non-state actors, as project documents, as well as the findings of the operational entity, are made public on the Internet and comments are invited. In case of review, two Board members, possibly supported by outside experts, examine the request, and the Board adopts the final decision. More recently, the Executive Board has set up a Registration and Issuance Team (comprised of independent experts and chaired by a Board member) that routinely assesses the requests and alerts the Board, if a review is appropriate (Kyoto Protocol 2006c, Annex 43). Reviews are mainly requested because of doubts about the additionality of the project and about the correct application of the approved methodologies. They tend to result in the more stringent appraisal of projects (http://www.cdm.unfccc.int/projects).

In the review process, the discretion of the Executive Board is limited by accountability mechanisms similar to those related to the approval of new methodologies (see above: The Approval of Assessment Methodologies). It cannot request reviews at will, because the scientific opinion submitted by the Registration and Issuance Team, which is made up of external experts, can only be rejected with good reasons. During the process, the internal restriction imposed on the body by its composition tends to preclude bargaining. Finally, opportunistic decisions would undermine the reputation of the Board, as its activity is closely observed by many states and non-state actors.

Having effectively sorted out the latent intergovernmental conflict among the member states from day-to-day approval activities, the institutional arrangement has tacitly created a new transnational tension between the mostly private applicants and the public approval authorities that produced demand for an additional appeal procedure. Private firms, including multinationals from both Annex I and Non-Annex I countries, play an important role within the CDM, because their profit-seeking interests generate projects on which the success of the CDM depends. Accordingly, the approval apparatus is increasingly subject to market-based accountability (Grant and Keohane 2005, 36-7). Especially wrongly negative decisions in the certification stage would immediately diminish the

\footnotetext{
3 As of May 2008, 18 operational entities had been designated by the CoP (http://www.cdm.unfccc.int/DOE). Current operational entities include: the British Société Générale de Surveillance UK (SGS), the German Technischer Überwachungsverein (TÜV), and the Norwegian Det Norske Veritas (DNV).
} 
reputation of the whole $\mathrm{CDM}$ mechanism, because private firms would not dare to invest in future CDM projects, if they could not be sure that resulting emission reductions were sincerely certified. Accordingly, applicants and investors require reliable legal protection. However, the existing approval procedure is primarily directed at preserving the public interest in the proper operation of the CDM. Applicants may instigate review proceedings to challenge the findings of the operational entities involved, but there is not yet a formal procedure for reviewing the final decisions of the Executive Board. The absence of an institutionalized appeal procedure might encourage aggrieved investors to bring cases before suitable domestic courts.

Driven by this transnational tension within the CDM scheme, an additional appeal procedure is currently evolving. In December 2006, the CoP approved an interim procedure that is, in the first place, motivated by the intention to secure the privileges and immunities of the Board members (see Decision 9/CMP.2, Kyoto Protocol 2006a, 34-35 and Kyoto Protocol 2006b, 20-21). It enables applicants to submit complaints against Board decisions to the head of the Convention Secretariat (Decision 9/CMP.2, Kyoto Protocol 2006a, 34-35). The Secretariat is empowered to analyze such complaints and may recommend that the Executive Board revise relevant decisions. There have already been several complaints, two of which have led to revised Board decisions (information provided by the Secretariat). Moreover, the Subsidiary Body on Implementation is currently considering the establishment of a further dispute settlement mechanism that would allow some kind of formal appeal (Kyoto Protocol 2006b, 17).

The new complaint procedure introduces a completely new layer of accountability into the approval procedure, but it does not fundamentally change the existing arrangement. Henceforth, project-specific decisions of the Executive Board will be under scrutiny by another body. Although this might jeopardize the independence of the Board if abused by the newly introduced agent, delegation of supervisory functions to another trustee, such as the Subsidiary Body on Implementation, will almost automatically reinforce the rational expectation of Board members that poorly reasoned decisions will not hold, and that the procedural rights of applicants must be honored. Judicial review by specialized bodies is known to foster legalization of social relations, because it privileges legal arguments over power (Kingsbury, Krisch, and Stewart 2005, 44-6; Shapiro 2001). Legal protection of the rights of investors will thus reinforce the accountability of the trustee agent that has been invested by the member states with far-reaching competencies to overcome their own credible commitment problems.

Altogether, the procedures for the validation and registration of new CDM projects and for the certification of emission reduction credits limit the discretion of all decision-making bodies. It is difficult to pursue partisan interests unless they are supported by convincing reasons. The operational entities risk losing their reputation, and their accreditation, when testifying too generously, and the Executive Board cannot, in light of approved methodologies, afford to deviate from problem-adequate decisions. As procedures are highly transparent, both the operational entities and the Executive Board are supervised by member states and the interested public, including NGOs. These external actors can, in turn, only influence a particular decision, if their submissions are accompanied by reasons that convince the members of the Executive Board. Their activity constitutes an additional "fire alarm" arrangement. Whereas this procedure does not exclude error or the exploitation of a residual margin of discrete choice, it can be expected to ensure decisions that are not distorted by the prevailing distribution of power. However, the current discussion concerning an additional appeal procedure demonstrates that the existing accountability arrangements might still be tightened without re-politicizing approval decisions. 
TABLE 2. Increasing Activity of the Approval Apparatus (Cumulative Figures)

\begin{tabular}{lcrr}
\hline & 2005 & 2006 & 2007 \\
\hline Approved methodologies & 52 & 62 & 91 \\
Rejected methodologies & 57 & 79 & 112 \\
Registered projects & 14 & 387 & 895 \\
Rejected projects & - & 6 & 52 \\
\hline
\end{tabular}

Source. Kyoto Protocol Secretariat.

\section{How the Approval Apparatus Deals with Difficult Cases}

A reliable decision-making system must be capable of convincingly dealing with difficult cases. By the end of 2007, more than 200 methodologies and almost 1,000 projects had been validated (see Table 2). The appraisal of most methodologies and projects does not pose particular difficulties for the approval apparatus. While all well-designed decision-making systems can satisfactorily process the easy cases for which they have been established, difficult cases put to a test the ability of the apparatus to actually sort out parochial interests and to produce well-reasoned, and therefore widely acceptable, decisions.

In this section, we examine three of the comparatively few cases that posed serious difficulties to the apparatus and illustrate different types of obstacle to reason-based decision making. The selected cases are thus decidedly not representative for the universe of cases, because the selection is strongly biased toward the difficult ones. Our main indicators for the existence of difficulties within the approval procedure are the occurrence of lasting conflict among the decision makers or the repeated consideration, or modified appraisal, of an application.

\section{The Graneros Fuel Switching Project: Disputed Assessment of Additionality}

The Graneros project illustrates how the system assesses, in comparatively "regular" cases, additionality of emission reductions in light of considerable uncertainty and lacking precedents. In May 2003, the Swiss company Nestlé applied for a project intended to switch the fuel used at its food plant in Graneros (Chile) from coal and diesel to natural gas. The measures would be additional, because in this region of Chile gas is more expensive than coal. The generated credits were to be sold to a Japanese power company (MGM International Assurance Ltd. 2004). The project was supposed to reduce emissions by $432,960 \mathrm{~T}$ of $\mathrm{CO}_{2}$ over a 21-year period, with a market value of up to $10,000,000$ US\$ at current market prices (May 2008).

The submitted assessment methodology had to be revised before it was eventually approved. The desk reviewers of the Methodologies Panel and two public comments criticized that the additionality criterion were not met, if the project included replacement of equipment from the 1980s (http://www.cdm.unfccc.int/ methodologies). The Panel recommended a revision and resubmission (B-rating), and suggested inter alia that the project should not increase the capacity and lifetime of the existing facility (Kyoto Protocol 2003e). The Executive Board followed the recommendation of the Methodologies Panel. Neither the Board member from Japan nor the alternates from Chile and Switzerland voiced any national interests or tried to change the decision. (Kyoto Protocol 2003a, 3-4, and broadcast of the meeting at http://unfccc.int/cdm.) Upon incorporation of the required changes, the Methodologies Panel recommended acceptance, and the Executive Board decided to register the methodology (Kyoto Protocol 2003b, 4).

Validation led to further adjustments of the project design and considerably reduced the amount of emission credits involved. In response to changes of the 
methodology, the project design had already been slightly downsized. The designated operational entity, namely Det Norske Veritas, required further changes, concerning, inter alia, the lifetime of the boilers. Nestle had also to prove that its environmental policy did not require realization of the project anyway. Eventually, the operational entity issued a request for registration. However, the Executive Board reviewed the project upon request by three of its members (Joint Implementation Network 2004, 10-11). It complained, inter alia, that still machinery from the 1950s and 1960s was involved, which would have to be replaced in the foreseeable future. Following further changes, the project was registered, but the crediting period was limited to the lifetime of the oldest existing equipment within the plant, which significantly reduced the size of the project (Kyoto Protocol 2005b, 8-9).

Altogether, the approval procedure operated as expected. While the applicants attempted to overestimate emission reductions and proposed an assessment methodology that confirmed their estimates, the Methodologies Panel and the Executive Board took their assessment function very seriously without engaging in a politicized struggle over distributive effects. The approval of assessment methodologies and the validation of related projects were carefully observed by competent non-state actors. Shortly after the registration of the project, the Executive Board adopted guidelines for treating the lifetime of plants and equipment based upon this case (Kyoto Protocol 2005c, 5-6).

\section{VE'M do Brasil Avoided Fuel Switch Project: Doubts about the Eligibility of an Entire Project Category}

The V\&M do Brasil project demonstrates that the allegedly technical assessment of CDM projects can stir principled conflict about entire project categories. The methodology applied for in March 2003 was the second submitted to the Methodologies Panel. The project was intended to allow the Brazilian steel producing plant to continue using charcoal instead of switching to the more environmentally harmful, but (according to the project developers) cheaper coke. At that time, the plant used charcoal from its own eucalyptus-plantations as a fuel. The emission credits were to be sold to Toyota Tsusho from Japan and the International Finance Corporation, purchasing emission certificates for the Dutch government. The additionality of emission reductions from "avoided fuel switch projects" is difficult to demonstrate, because credits are claimed for leaving everything as it is. The applicants submitted price comparisons between charcoal and coke, and they argued that several steel-producers in Brazil had already switched to coke.

A first assessment methodology was rejected upon unanimous expert advice. Upon preparation by the desk reviewers, the Methodologies Panel recommended rejection of the methodology, because the application did not demonstrate convincingly that coke was really cheaper than charcoal (Kyoto Protocol 2003f). The Executive Board accepted this rating. Although the discussion in the Board did not focus on details, it revealed that the members were still slightly unsure about how to proceed in light of the pioneer case.

In the second round, the category of "avoided fuel switch projects" created considerable tension among the experts involved. Only a few months after the first rejection, the project developers handed in a new methodology (NM0029, IFC-Netherlands Carbon Facility and Toyota Tsusho 2003). While some of the criticized aspects had been altered, the project was supposed to generate almost as many credits as the original version. Public comments recognized improvements but still found mistakes, ambiguities, and subjective decisions. Some of them openly doubted that the project type was suitable for the CDM (Kyoto Protocol 2003g), especially as the "long-term benefit," a basic eligibility criterion 
for CDM projects, was difficult to assess. The desk reviews complained about incomplete and unclear data and strongly criticized the dependency on assumptions. One expert proved that there had been investments in new charcoal projects in Brazil and that the project might thus be cost-effective in itself. However, the Methodologies Panel was not able to find a common position on the methodology. It considered the issue to be a political one, because it dealt with a whole project category. Consequently, it asked for "guidance of the Board...based on the...immaterial nature of the project activity and the moral hazard that is related to the fact that the project activity consists of continuing current practice" (Kyoto Protocol 2003d, 3).

The Executive Board was also deeply divided on the issue. In a fair debate referring to the CDM criteria and other project examples, some members advocated accepting the project type, while others desired to reject it, and a third group supported a case-by-case approach (Kyoto Protocol 2003c, 3, broadcast of the meeting at http://unfccc.int/resource/webcast/cdm/eb12/index.html). Finally, the Methodologies Panel was instructed to develop further recommendations, but could not reach a consensus (Kyoto Protocol 2004a, 3). After this failure, the issue was put on hold for 11 months. In December 2004, the discussion in the Board was repeated, with similar positions (Kyoto Protocol 2004b, 4). Many members opposed projects based upon continuation of existing practices, as they are technically difficult to monitor and provide a potential for blackmail, because companies could threaten to switch fuel if they did not receive emission credits. Other members argued that acceptable single cases might be found. Eventually, the Board achieved consensus on assessing projects case-by-case. On this basis, the Methodologies Panel recommended rejecting the submitted methodology, because of lacking transparency and limited possibilities for validating the project (Kyoto Protocol 2005e, 8). The Board approved this recommendation without discussion (Kyoto Protocol 2005d, 6).

This case draws attention to the limits of deliberative decision making in the CDM approval system and the tendency of the actors involved to sidestep principled, and therefore more contentious, issues in favor of mutually agreed "technical" solutions. The project generated a clash between those fearing that avoided fuel switch project would undermine the additionality criterion and those others fearing that too strict an interpretation of the criteria would jeopardize the relevance of the CDM altogether. This conflict was difficult to solve at the level of principle. Therefore, the Board agreed eventually on the case-by-case consideration of projects. However, this compromise did not extend to the particular project-related methodology. Concerning this more limited, and therefore more "technical," issue, both experts and Board members reached agreement.

\section{The HFC Avoidance Projects: Can Supplementary Criteria be Applied?}

The Hydrofluorocarbon (HFC) 23 controversy demonstrates that decision making is immediately threatened to be politicized, if the approval apparatus cannot rely on general criteria. In April 2003, project developers submitted a methodology and concepts for a HFC decomposition project in Ulsan (South Korea) and for a project reducing greenhouse gas emissions by thermal oxidation of HFC 23 in Gujarat (India). Both projects were intended to destroy HFC 23, a gas with a high-global warming potential, which is regulated under the Kyoto Protocol. This gas is a byproduct of Hydrochlorofluorocarbon (HCFC) 22, an ozone-depleting substance used as a refrigerant and regulated under the Montreal Protocol. The relevant methodology NM0007 was approved accordingly as AM0001 (Kyoto Protocol 2003a, 3).

After the approval of the methodology (i.e., during validation of the projects in question), public interventions raised general concern regarding the implications of the project. Projects of this type threatened to create an overly high 
return on investment because the costs for destroying HFC 23 are very low, whereas the amount of emissions credits gained is high. It could become attractive to produce HCFC 22 exclusively to gain HFC 23 for CDM projects (Watanabe and Sterk 2007, 3). A public comment doubted that the project was in conformity with basic principles of the Kyoto Protocol (http://www.cdm. unfccc.int/Projects). A U.S. firm disputed the proposed calculation, and a Swiss institute spelled out the problems of interaction with the Montreal Protocol (http://www.cdm.unfccc.int/methodologies/inputam0001).

The approval apparatus faced serious difficulties in dealing with this issue, because the additionality of HFC 23 reductions had always been undisputed. While the project type would be acceptable, if the CDM criteria were taken literally, it seemed to violate the intentions of the Protocol and raised issues of its relationship with other international institutions (Schneider, Graichen, and Matz 2005). Recognizing that the existing CDM criteria did not provide a firm foundation for the settlement of the conflict, the Board requested guidance from the CoP (Kyoto Protocol 2004b, 3). The CoP referred the matter to the Subsidiary Body for Scientific and Technological Advice (SBSTA). During SBSTA 22, 23, and 24, especially China, which hosts several HFC-23 projects, rejected further regulation (see Webcast on SBSTA 24, available at http://unfccc.int/resource/ webcast/sb24/templ/ovw_str_sbi_english.html). In contrast, the European Union and most developing countries favored a strict course to ensure the environmental integrity of the Protocol. Both the CoP and the SBSTA are still considering the matter.

In the meantime, the Executive Board struggled with interim measures. In a closed session, it decided to put the methodology on hold to enable a review by the Methodologies Panel (Kyoto Protocol 2004c, 3). This was a remarkable exception to the usual transparency of Board decision-making and stirred concern of possible over-regulation behind closed doors. The Methodologies Panel was faced with a revised methodology that excluded new HCFC 22 plants and required conservative calculations for existing plants. This methodology, viewed as restrictive by industry and consultants (MGM International Assurance Ltd 2005, 17), was later approved (AM0001-vers.3; Kyoto Protocol 2005d, 4, and $2005 \mathrm{~b}, 5)$. The two original projects in South Korea and India had been temporarily put on hold (Kyoto Protocol 2004b, 7), but were later registered, because their validation had been based upon the original methodology. Other HFC 23projects have been registered in the meantime based upon the new, comparatively restrictive methodology.

Where substantive decision criteria are lacking, reason-based administrative decision making is immediately threatened with becoming politicized. Hence, this case demonstrates on the one hand, that conflicts on the approval of CDM projects are not at all trivial or of minor importance. There is a potential for fierce battle. Stakeholders and decision-makers tend to pursue preferences, if there is an opportunity. On the other hand, it emphasizes that the absence of clear guidance provides such opportunity for the pursuit of partisan interests, because the commonly accepted point of reference is missing. Clarifying such guidelines is a matter for the political bodies established under the Protocol. However, these bodies faced similar difficulties. Against this backdrop, the approval apparatus struggled to reduce the scope of the underlying problem technically. By accepting a restrictive methodology that avoids the main problem of encouraging undesired production of greenhouse gases (and ozone-depleting substances) to create new CDM projects, the Executive Board eventually resorted to a strict interpretation of its mandatory criteria, and has continued to do so in revisions and clarifications of the methodology. Remarkable is also the importance of the seemingly irrelevant accountability of the approval apparatus to the broader public. Public interventions drew attention 
to the originally unrecognized problems involved in HFC 23 projects, and public protest caused the Methodologies Panel and the Executive Board to resort to an open decision-making process. Hence, the controversy emphasizes the need for uncontested substantive decision criteria and highlights the power of an external accountability mechanism relying on an informed, albeit selected, public.

\section{Conclusion}

Assigning decision-making competencies to trustee agents creates a triadic constellation. Analysts of delegation patterns emphasize that the relationship between principals and agents is hierarchical. The former grant, and can revoke, authority that is limited in scope and time, while the latter (should) operate within the limits of granted authority. This is true for closely controlled agents and comparatively autonomous trustees alike. However, trustee agents are largely protected from direct intervention by their principals into their day-to-day business. Their autonomy undermines the effectiveness of the fundamentally hierarchical relationship with their principals, because they are deliberately charged with not closely following the preferences of their principals in a given decision situation. Yet, even trustees are not entitled to replace their principals' preferences simply with their own ones. Instead, they are commissioned to decide according to some previously established decision criteria that are defined by their principals and reflect the latter's long-term interests. These decision criteria intervene as a third entity into the otherwise dyadic relationship between principals and agents. In a successful trusteeship constellation, principals will, in their own well-perceived long-term interest, only intervene into the day-to-day business, if a trustee produces decisions that are not in line with the previously established decision criteria. And a trustee agent can reject possible interference by her principals by referring to these criteria.

As any other agent, trustees may abuse their powers and must, therefore, be made accountable for their decisions. Ideally, accountability arrangements ought to preserve the autonomy of a trustee from her principals' interference into her regular decision making as fully as possible. At the same time, they ought to diminish as far as possible the trustee's ability to sidestep or ignore the externally provided decision criteria. For this reason, institutional arrangements must rely predominantly on internal, or horizontal, accountability mechanisms. The most important ones are the careful composition of a collective trustee agent, the division of labor within the decision process among several trustee agents, and the giving reasons requirement. Complaint procedures relying on decisions of yet other trustees, such as judicial review, can sustain the rational expectation that unconvincing or badly reasoned decisions do not prevail. Trustees can also be made selectively accountable to the wider public, because their task is to identify options that are particularly well-reasoned in light of the externally provided decision criteria. In contrast, the ever present accountability of a trustee to her principals will undermine the delicate arrangement, unless it remains latent and focuses only on the overall direction of the decision process, rather than its details.

The member states of the Kyoto Protocol have not only assigned the approval of CDM projects to an Executive Board, they have also refrained from intervening into the day-to-day business of this trustee. The arrangement does not entirely replace political decisions with technocratic ones. By defining the decision criteria, and by readjusting them in light of experienced difficulties, the CoP fulfills an important function within this complex decision-making system. The exemption of certain types of projects, such as nuclear plants and some forms of sinks, limits the scope of the CDM approval mechanism, but it does not jeopardize its proper operation within its area of competence. 
The CDM Executive Board is woven into a web of internal accountability mechanisms. Together, these mechanisms shall ensure that approval decisions are made in accordance with the decision criteria provided by the $\mathrm{CoP}$ and help protect decisions from distortion by partisan interests of states and non-state actors. Composition of the Board and relevant decision rules create a consensusbased situation of committee governance and preclude one camp from outvoting the other. The approval procedures divide decision functions among a number of involved actors. The Executive Board is formally in charge, but applicants elaborate methodologies and submit project proposals, the Methodologies Panel evaluates the assessment methodologies, and operational entities recruited from outside validate projects based upon a recognized methodology and verify them before emission credits are released. Still missing from this multifaceted accountability arrangement is a layer that protects the rights and interests of public and private investors in CDM projects. If well-designed, the currently emerging complaint procedure can reinforce the internal accountability of the Board. For this purpose, the reviewing body must itself be a trustee that is effectively shielded from case-specific interference by the principals or other stakeholders.

External accountability plays a minor role. While accountability of the Board to its principals remains as latent as it should be, external accountability to the broader public has become a significant component of the assessment process. The procedures provide several points of entry for comments from the public that help attract relevant but dispersed knowledge. This form of external accountability has little to do with transnational democracy, or with "civil society's" alleged participation rights. It is almost exclusively directed at improving the quality, and acceptability, of the adopted decisions. Participation is in fact very selective. In every single case, only a handful of experts from NGOs, competent institutes, and possibly also from state bureaucracies or competing firms, will dispose of the knowledge and skills necessary to prepare a convincing intervention.

Altogether, this procedure promises to facilitate impartial judgment of submissions in light of the valid decision criteria, and to discourage partisan intervention, unless it is based upon convincing arguments. Yet, the analysis of critical cases points to some obstacles to generating well-reasoned, and therefore acceptable, decisions. The Graneros case illustrates how a submission is, in the presence of uncertainty, only gradually adjusted over time. The V\&M do Brasil case draws attention to the interpretability of the additionality criterion. The lasting conflict between two camps of experts over "avoided fuel switch projects" was only overcome by sidestepping issues of principle and by resorting to a case-specific decision. The HFC 23 case demonstrates the limits of the technocratic decision-making rationale in cases of an alleged necessity to apply additional criteria. The eventually identified interim solution reflects the fact that the approval system cannot, and should not, invent its own criteria, because this would inevitably undermine the vertical division of labor between the trustee and her principals.

The CDM approval apparatus demonstrates that delegation of decision-making authority to administrative trustee agents promises to enhance the governance capacity of international institutions and the quality of the decisions produced. The two main prerequisites for successful trusteeship governance are fulfilled. First, there is a carefully delimited division of labor between principals and trustee agent which is adhered to by both sides. Second, the trustee invested with decision-making authority is effectively held accountable for her decisions and cannot easily ignore the existing decision criteria. Hence, the CDM arrangement provides a model for nonpartisan international regulation in the presence of the demand for continuous decision making in light of general decision criteria and serious credible commitment problems that encourage the member states of an international institution to delegate regulation to a comparatively autonomous trustee agent. 


\section{References}

Alter, Karen. 2006. "Delegation to International Courts and the Limits of Recontracting Power." In Delegation and Agency in International Organizations, ed. Darren G. Hawkins, David A Lake, Daniel L. Nielsen, and Michael J. Tierney. Cambridge: Cambridge University Press.

Alter, Karen. 2008. "Agents or Trustees? International Courts in Their Political Context." European Journal of International Relations 14 (1): 33-63.

Barnett, Michael, and Martha Finnemore. 2004. Rules for the World: International Organizations in Global Politics. Ithaca, NY: Cornell University Press.

Boehmer-Christiansen, Sonja, And Aynsley Kellow. 2002. International Environmental Policy: Interests and the Failure of the Kyoto Process. Cheltenham: Edward Elgar.

Brennan, Geoffrey, and James Buchanan. 1985. The Reason of Rules. Constitutional Political Economy. Cambridge: Cambridge University Press.

Burley, Ann-Marie, And Walter Mattli. 1993. "Europe Before the Court.” International Organization 47 (1): 41-76.

Clark, Dana, Jonathan Fox, and Kay Treakle, eds. 2003. Demanding Accountability. Civil-Society Claims and the World Bank Inspection Panel. Lanham: Rowman \& Littlefield.

Elster, Jon. 1979. Ulysses and the Sirens. Studies in Rationality and Irrationality. Cambridge: Cambridge University Press.

Elster, Jon. 1989. The Cement of Society: A Study of Social Order. Cambridge: Cambridge University Press.

Elster, Jon. 1998. "Deliberation and Constitution Making." In Deliberative Democracy, ed. Jon Elster. Cambridge: Cambridge University Press.

Epstein, David, and Sharyn O'Halloran. 1999. Delegating Powers: A Transaction Cost Politics Approach to Policy Making Under Separate Powers. Cambridge: Cambridge University Press.

Garrett, Geoffrey, R. Daniel Kelemen, and Heiner Schulz. 1998. "The European Court of Justice, National Governments, and Legal Integration in the European Union." International Organization 52 (1): 149-176.

Garrett, Geoffrey, and George Tsebelis. 1996. “An Institutional Critique of Intergovernmentalism." International Organization 52 (2): 269-299.

Gehring, Thomas. 1999. "Arguing, Bargaining and Functional Differentiation of Decision-Making: The Role of Committees in European Environmental Process Regulation." In EU Committees. Social Regulation, Law and Politics, ed. Christian Joerges, and Ellen Vos. Oxford: Hart.

Gehring, Thomas, and Sebastian Krapohl. 2007. "Supranational Regulatory Agencies Between Independence and Control: The EMEA and the Authorisation of Pharmaceuticals in the European Single Market." Journal of European Public Policy 14 (2): 208-226.

Gehring, Thomas, and Eva Ruffing. 2008. "When Arguments Prevail Over Power: The CITES Procedure for the Listing of Endangered Species." Global Environmental Politics 8 (2): 123-148.

Gilardi, Fabrizio. 2007. "The Same, But Different: Central Banks, Regulatory Agencies, and the Politics of Delegation to Independent Agencies.' Comparative European Politics 5 (3): 303-327.

Grant, Ruth W., And Robert O. Keohane. 2005. "Accountability and Abuses of Power in World Politics." American Political Science Review 99 (1): 29-43.

Hawkins, Darren G., David A Lake, Daniel L. Nielsen, and Michael J. Tierney. 2006. "Delegation Under Anarchy: States, International Organizations and Principal Agent Theory." In Delegation and Agency in International Organizations, ed. Darren G. Hawkins, David A. Lake, Daniel L. Nielsen, and Michael J. Tierney. Cambridge: Cambridge University Press.

Huber, John D. 2000. "Delegation to Civil Servants in Parliamentary Democracies." European Journal of Political Research 37 (3): 397-413.

IFC-Netherlands Carbon Facility and Toyota Tsusho. 2003. V\&M do Brasil Avoided Fuel Switch Project. Project Design Document, September. Washington/Nagoya/Belo Horizonte. Available at http://cdm.unfccc.int/UserManagement/FileStorage/FS_89476094, (Accessed in December 2006.)

Joint Implementation Network. 2004. Joint Implementation Quarterly October. Available at www.jiqweb. org/index.htm. (Accessed in July 2009.)

Keech, William R. 1995. Economic Policy: The Costs of Democracy. Cambridge: Cambridge University Press.

Kenber, Mark. 2005. "The Clean Development Mechanism: A Tool for Promoting Long-Term Climate Protection and Sustainable Development." In Climate Change and Carbon Markets: A Handbook of Emissions Reductions Mechanisms, ed. Farhana Yamin. London: Earthscan. 
Keohane, Robert O. 2003. "Global Governance and Democratic Accountability.” In Taming Globalization: Frontiers of Governance, ed. David Held, and Mathias Koenig-Archibugi. London: Polity Press.

Kiewiet, Roderick, and Mathew D. McCubbins. 1991. The Logic of Delegation: Congressional Parties and the Appropriations Process. Chicago, IL: University of Chicago Press.

Kingsbury, Benedict, Nico Krisch, and Richard B. Stewart. 2005. "The Emergence of Global Administrative Law." Law and Contemporary Problems 68 (1): 15-61.

Koremenos, Barbara, Charles Lipson, and Duncan Snidal. 2001. "The Rational Design of International Institutions." International Organization 55 (4): 761-799.

Kyoto Protocol 2002: Executive Board of the Clean Development Mechanism, 2nd Meeting, Report, Doc. CDM-EB-02, January 22, 2002.

Kyoto Protocol 2003a: Executive Board of the Clean Development Mechanism, 10th Meeting, Report, Doc. CDM-EB-10, July 29, 2003.

Kyoto Protocol 2003b: Executive Board of the Clean Development Mechanism, 11th Meeting, Report, Doc. CDM-EB-11, October 30, 2003.

Kyoto Protocol 2003c: Executive Board of the Clean Development Mechanism, 12th Meeting, Report, Doc. CDM-EB-12, December 2, 2003.

Kyoto Protocol 2003d: Report of the Eighth Meeting of the Methodologies Panel, Bonn, November 3-5, 2003. Available at http://cdm.unfccc.int/Panels/meth/Meth08rep_ext.pdf. (Accessed July 29, 2003.)

Kyoto Protocol 2003e: Methodologies Panel Recommendation to the Executive Board on NM0016 Graneros Fuel Switching Project in Chile, Doc. CDM-NMmp0016, July 8, 2003.

Kyoto Protocol 2003f: Methodologies Panel Recommendation to the Executive Board on NM0002 V\&M do Brasil Avoided Fuel Switch Project, Doc. CDM-NMmp0002, May 23, 2003.

Kyoto Protocol 2003g: Public Input on V\&M do Brasil Avoided Fuel Switch Project by Lambert Schneider. Available at http://cdm.unfccc.int/UserManagement/FileStorage/NM0029pu\%20 Oeko_Institut.pdf. (Accessed in December 2006.)

Kyoto Protocol 2004a: Internal Report of the Tenth Meeting of the Methodologies Panel, Bonn, April 27-30, 2004. Available at http://cdm.unfccc.int/Panels/meth/meeting/04/Meth10_rep_ ext.pdf

Kyoto Protocol 2004b: Executive Board of the Clean Development Mechanism, 17th Meeting, Report, Doc. CDM-EB-17, December 6, 2004.

Kyoto Protocol 2004c: Executive Board of the Clean Development Mechanism, 15th Meeting, Report, Doc. CDM-EB-15, September 3, 2004.

Kyoto Protocol 2005a: Report of the Conference of the Parties Serving as the Meeting of the Parties to the Kyoto Protocol on its First Session, Held at Montreal from November 28-December 10, 2005; Addendum, Part Two: Action Taken by the Conference of the Parties Serving as the Meeting of the Parties to the Kyoto Protocol at its First Session; Doc. FCCC/KP/CMP/2005/8/Add.1, March 30, 2006.

Kyoto Protocol 2005b: Executive Board of the Clean Development Mechanism, 19th Meeting, Report, Doc. CDM-EB-19, May 14, 2005.

Kyoto Protocol 2005c: Executive Board of the Clean Development Mechanism, 22nd Meeting, Report, Doc. CDM-EB-22, November 25, 2005.

Kyoto Protocol 2005d: Executive Board of the Clean Development Mechanism, 18th Meeting, Report, Doc. CDM-EB-18, February 25, 2005.

Kyoto Protocol 2005e: Methodologies Panel Recommendation to the Executive Board on NM0029 V\&M do Brasil Avoided Fuel Switch Project, Doc. CDM-NMmp0029, January 28, 2005.

Kyoto Protocol 2006a: Report of the Conference of the Parties Serving as the Meeting of the Parties to the Kyoto Protocol on its Second Session, held at Nairobi November 6-17, 2006; Addendum, Part Two: Action Taken by the Conference of the Parties Serving as the Meeting of the Parties to the Kyoto Protocol at its Second Session; Doc. FCCC/KP/CMP/2006/10/Add.1, March 2, 2007.

Kyoto Protocol 2006b: Report of the Subsidiary Body for Implementation, 25th Session, Held at Nairobi, Kenya, November 6-14, 2006; Doc. FCCC/SBI/2006/28, December 18, 2006.

Kyoto Protocol 2006c: Executive Board of the Clean Development Mechanism, Twenty-Fifth Meeting, Report, Doc. CDM-EB-25, July 21, 2006.

Kyoto Protocol 2008: Executive Board of the Clean Development Mechanism, 39th Meeting, Report, Doc. CDM-EB-39, May 16, 2008.

Lefevre, JÜrgen. 2005. "Linking Emissions Trading Schemes: The EU ETS and the 'Linking Directive'.' In Legal Aspects of Implementing the Kyoto Protocol Mechanisms: Making Kyoto Work, ed. David Freestone, and Charlotte Streck. Oxford: Oxford University Press. 
Majone, Giandomenico. 2001a. "Nonmajoritarian Institutions and the Limits of Democratic Governance: A Political Transaction-Cost Approach." Journal of Institutional and Theoretical Politics 157: 57-78.

Majone, Giandomenico. 2001b. "Two Logics of Delegation: Agency and Fiduciary Relations in EU Governance." European Union Politics 2 (1): 103-122.

Matsuo, Naoki. 2004. "The Clean Development Mechanism: Issues and Opportunities." International Review for Environmental Strategies 5 (1): 233-240.

McCubbins, Mathew D., Roger G. Noll, and Barry R. Weingast. 1987. “Administrative Procedures as Instruments of Political Control." Journal of Law, Economics, and Organization 3 (2): 243-277.

McCubbins, Mathew, and Thomas Schwartz. 1987. "Congressional Oversight Overlooked: Police Patrols Versus Fire Alarm.” American Journal of Political Science 28 (1): 165-179.

Mejjer, Ernestine, and Jacob Werksman. 2005. "Keeping it Clean: Safeguarding the Environmental Integrity of the Clean Development Mechanism." In Legal Aspects of Implementing the Kyoto Protocol Mechanisms: Making Kyoto Work, ed. David Freestone, and Charlotte Streck. Oxford: Oxford University Press.

MGM International Assurance Ltd. 2004: Graneros Pant Fuel Switching Project, Project Design Document; Buenos Aires. Available at http://cdm.unfccc.int/UserManagement/FileStorage/ FS_356726815. (Accessed January 2007.)

MGM International Assurance Ltd. 2005. World CDM Projects Review as of March 2005. Available at http://www.mgminter.com/documents (Accessed January 2007.)

Michaelowa, Axel. 2005. "Clean Development Mechanism und Joint Implementation." In Emissionshandel, ed. Michael Lucht, and Gordon Spangardt. Heidelberg: Springer.

Moe, Terry. 1990. "The Politics of Structural Choice." In Organization Theory: From Chester Barnard to the Present and Beyond, ed. Oliver E. Williamson. New York: Oxford University Press.

Moravcsik, Andrew. 1998. The Choice for Europe: Social Purpose and State Power From Messina to Maastricht. Ithaca, NY: Cornell University Press.

Netto, Maria, and Kai-Uwe Barani Schmidt. 2005. "CDM Project Cycle and the Role of the UNFCCC Secretariat.” In Legal Aspects of Implementing the Kyoto Protocol Mechanisms: Making Kyoto Work, ed David Freestone, and Charlotte Streck. Oxford: Oxford University Press.

Nielson, Daniel L., and Michael J. Tierney. 2003. "Delegation to International Organizations: Agency Theory and World Bank Environmental Reform." International Organization 57 (2): 241276.

Nimzawa, Hidenori. 2003. "On the Additionality of GHG Reduction." In International Frameworks and Technological Strategies to Prevent Climate Change, ed. Takamitsu Sawa. Tokyo: Springer.

O’Donnell, Guillermo. 1999. "Horizontal Accountability in New Democracies." In The Self-Restraining State: Power and Accountability in New Democracies, ed. Andreas Schedler, Larry Diamond, and Marc F. Plattner. Boulder, CO: Lynne Rienner.

Oberthür, Sebastian, and Hermann E. Otт. 1999. The Kyoto Protocol: International Climate Policy for the 21st Century. Berlin: Springer.

Pollack, Mark A. 1997. "Delegation, Agency, and Agenda Setting in the European Community.", International Organization 52 (1): 99-134.

Rawls, John. 1971. A Theory of Justice. Cambridge: Harvard University Press.

Repetto, Robert. 2001. "The Clean Development Mechanism: Institutional Breakthrough or Institutional Nightmare?" Policy Sciences 43 (3/4): 303-327.

Risse, Thomas. 2000. “'Let's Argue!' Communicative Action in World Politics.” International Organization 54 (1): 1-39.

Sales, Rodrigo, and Bruno Kherlakian Sabbag. 2007. "Environmental Requirements and Additionality Under the Clean Development Mechanism: A Legal Review Under the UNFCCC, the Kyoto Protocol, and the Brazilian Legal Framework on Climate Change." Yearbook of International Environmental Law 17 (2005): 235-257.

Sartori, Giovanni. 1987. The Theory of Democracy Revisited. Chatham: Chatham House.

Schelling, Thomas C. 1960. The Strategy of Conflict. Cambridge: MIT Press.

Schmitter, Phillippe C. 1999. "The Limits of Horizontal Accountability." In The Self-Restraining State. Power and Accountability in New Democracies, ed. Andreas Schedler, Larry Diamond, and Marc F. Plattner. Boulder, CO: Lynne Rienner.

Schneider, Lambert, Jakob Graichen, and Nele Matz. 2005. "Implications of the Clean Development Mechanism Under the Kyoto Protocol on Other Conventions: The Case of HFC-23 Destruction." ELNI Review (Environmental Law Network International) 2005 (1): 41-52. 
Scholz, Sebastian, and Ian Noble. 2005. "Generation of Sequestration Credits Under the CDM." In Legal Aspects of Implementing the Kyoto Protocol Mechanisms: Making Kyoto Work, ed. David Freestone, and Charlotte Streck. Oxford: Oxford University Press.

Schröder, HeIKe. 2001. Negotiating the Kyoto Protocol: An Analysis of Negotiation Dynamics in International Negotiations. Münster: Lit.

Scott, Colin. 2000. "Accountability in the Regulatory State." Journal of Law and Society 27 (1): $38-60$.

Shapiro, Martin. 1981. Courts: A Comparative Political Analysis. Chicago, IL: University of Chicago Press.

Shapiro, Martin. 1988. Who Guards the Guardians? Judicial Control of Administration. Athens: University of Georgia Press.

Shapiro, Martin. 2001. "The Institutionalization of European Administrative Space." In The Institutionalization of Europe, ed. Alec Stone Sweet, Wayne Sandholtz, and Neil Fligstein. Oxford: Oxford University Press.

Shapiro, Martin. 2002. "The Giving Reasons Requirement." In On Law, Politics, and Judicialization, ed. Martin Shapiro, and Alec Stone Sweet. Oxford: Oxford University Press.

Shepsle, Kenneth A. 1991. "Discretion, Institutions, and the Problem of Government Commitment." In Social Theory for a Changing Society, ed. Pierre Bourdieu, and James S. Coleman. Boulder, CO: Westview Press.

Stone Sweet, Alec. 2004. The Judicial Construction of Europe. Oxford: Oxford University Press.

Thatcher, Mark. 2002. "Regulation After Delegation: Independent Regulatory Agencies in Europe." Journal of European Public Policy 9 (6): 954-972.

UNFCCC. 2001. Report of the Conference of the Parties on its Seventh Session Held at Marrakesh. October 29 - November 10, 2001. Addendum, Part Two: Action Taken by the Conference of the Parties; Doc FCCC/CP/2001/13/Add.2. January 21, 2002.

Wara, Michael 2006. "Measuring the Clean Development Mechanism's Performance and Potential." Stanford Program on Energy and Sustainable Development. Working Paper No. 56. Available at http://iis-db.stanford.edu/pubs/21211/Wara_CDM.pdf (Last access in July 2009. Available today.)

Watanabe, Rie, and Wolfgang Sterk 2007. "Little Progress in Nairobi." In JIKO Info 2007/1. Wuppertal: Wuppertal Institute for Climate, Environment and Energy.

Yamin, Farhana, and Joanna Depledge. 2004. The International Climate Change Regime: A Guide to Rules, Institutions and Procedures. Cambridge: Cambridge University Press. 